\title{
Oxidation-reduction alternating copolymerization of germylene and $\mathrm{N}$-phenyl-p-quinoneimine
}

\author{
Satoru Iwata $^{1}$, Mitsunori Abe ${ }^{1}$, Shin-ichiro Shoda ${ }^{1}$ and Shiro Kobayashi ${ }^{1,2}$ \\ The germylenes bis[bis(trimethylsilyl)amido]germanium (1a) and bis[t-butyl-trimethylsilyl]amido]germanium (1b) were reacted \\ with $N$-phenyl-p-quinoneimine (2) to give copolymers ( $3 a$ and $3 b$ ) with alternating tetravalent germanium and $p$-aminophenol \\ units. The copolymerization took place smoothly at $0^{\circ} \mathrm{C}$ without added catalyst or initiator. 1 acted as a reductant monomer, \\ and 2 acted as an oxidant monomer (oxidation-reduction alternating copolymerization). Product copolymers were obtained in \\ very high yields and had high molecular weights. The copolymers were soluble in toluene, benzene, $n$-hexane and chloroform, \\ whereas they were insoluble in acetonitrile and acetone. Additionally, they were stable toward hydrolytic degradation. Electron \\ spin resonance (ESR) spectroscopic studies of the reaction suggested a structure of a stable germyl radical and a plausible \\ mechanism of biradical copolymerization.
}

Polymer Journal (2015) 47, 31-36; doi:10.1038/pj.2014.84; published online 8 October 2014

\section{INTRODUCTION}

Divalent germanium compounds (germylenes) and their tin analogs (stannylenes) continue to attract much interest in the organometallic chemistry area as heavy carbene analogs in the 14th group elements. ${ }^{1-5}$ In the polymerization chemistry field, there are few examples of their use as a monomer or a catalyst (initiator) because of the difficulty faced in handling them, such as inducing self-oligomerization, such difficulties are caused by the compounds' instability. Germylenes have a strong reducing ability and are generally observed as a short-lived reaction intermediate. The leading work by Lappert and co-workers, ${ }^{6}$ however, enabled the synthesis of stable germylenes. They showed that bulky alkyl, amino and phenoxy groups are effective substituents to prevent oligomerization and/or dimerization. Germanium-containing polymers were once derived from the substitution reaction of germanium dichloride, which led to polygermanes, ${ }^{7}$ and from the polyaddition reaction of a bisgermylene to an organic halide. ${ }^{8}$

These stable germylenes show potential to be very convenient and useful as monomers to prepare germanium-containing polymers because they are highly reactive as a reductant monomer to form two new bonds on the germanium atom. In fact, we have extensively developed new polymerization reactions by using a stable germylene $\left(\mathrm{GeR}_{2}, 1\right)$ as the monomer, as observed in the following examples. An acyclic germylene, bis[bis(trimethylsilyl)amido]germanium (1a), was copolymerized with various $p$-benzoquinones to give alternating copolymers that had high molecular weights in very high yields. The copolymerization took place at $-78^{\circ} \mathrm{C}$ without added catalyst. ${ }^{9}$ The biradical copolymerization mechanism was decidedly established through detailed nuclear magnetic resonance (NMR), electron spin resonance (ESR) and ultraviolet-visible (UV-VIS) spectroscopic investigations. ${ }^{10}$ Five- and six-membered cyclic germylenes, conversely, were copolymerized with $p$-benzoquinone derivatives in similar reaction conditions to afford novel 2:1 periodic copolymers with high molecular weights in very high yields. ${ }^{11}$ Interestingly, monomer 1 gave a poly(germanium enolate) with high molecular weight in high yield at $0{ }^{\circ} \mathrm{C}$ by the reaction of 1 with $\alpha, \beta$-unsaturated ketone. ${ }^{12-14}$ Monomer 1 and either ethylene sulfide or propylene sulfide underwent copolymerization at $0^{\circ} \mathrm{C}$, giving rise to $1: 1: \alpha$-periodic copolymers with eliminating ethylene or propylene. ${ }^{15}$ When thietane (four membered) was used in place of ethylene sulfide (three membered), 1 or a cyclic germylene was copolymerized with thietane in a 1:1 alternating fashion. ${ }^{16}$ Monomer 1 was also copolymerized with an acetylene monomer, leading to a copolymer at room temperature. This reaction required an $\mathrm{Rh}$ catalyst. ${ }^{17} \mathrm{~A}$ cyclic stannylene was similarly copolymerized with $p$-benzoquinone derivatives at $-42^{\circ} \mathrm{C}$, giving rise to $1: 1$ alternating copolymers in very high yields and having a molecular weight range from $1.1 \times 10^{5}$ to $5.7 \times 10^{3} .{ }^{18}$ In all of these copolymerizations, a germylene or stannylene acted as a reductant monomer, whereas a $p$-benzoquinone, $\alpha, \beta$-unsaturated ketone, acetylene, or cyclic sulfide behaved as an oxidant monomer (oxidation-reduction copolymerization). ${ }^{9-21}$ Of interest in the organometallic chemistry field, germylenes showed interesting reactivity toward $\alpha, \beta$-unsaturated carbonyl compounds and 2-vinylpyridine. ${ }^{22,23}$

In the present study, we report a new 1:1 oxidation-reduction alternating copolymerization of germylene ( $\mathbf{1} \mathbf{a}$ and $\mathbf{1} \mathbf{b}$ ) with $N$-phenylp-quinoneimine (2), in addition to a very brief oral presentation in part. ${ }^{24} 1$ acted as a reductant monomer, whereas 2 acted as an oxidant monomer, similar to a $p$-benzoquinone derivative. The resulting copolymers ( $\mathbf{3} \mathbf{a}$ and $\mathbf{3} \mathbf{b}$ ) had a tetravalent germanium unit and a

${ }^{1}$ Department of Materials Chemistry, Graduate School of Engineering, Tohoku University, Sendai, Japan and ${ }^{2}$ Center for Fiber and Textile Science, Kyoto Institute of Technology, Kyoto, Japan

Correspondence: Professor S Kobayashi, Center for Fiber and Textile Science, Kyoto Institute of Technology, Matsugasaki, Sakyo-ku, Kyoto 606-8585, Japan. E-mail: kobayash@kit.ac.jp

Received 12 June 2014; revised 10 August 2014; accepted 10 August 2014; published online 8 October 2014 


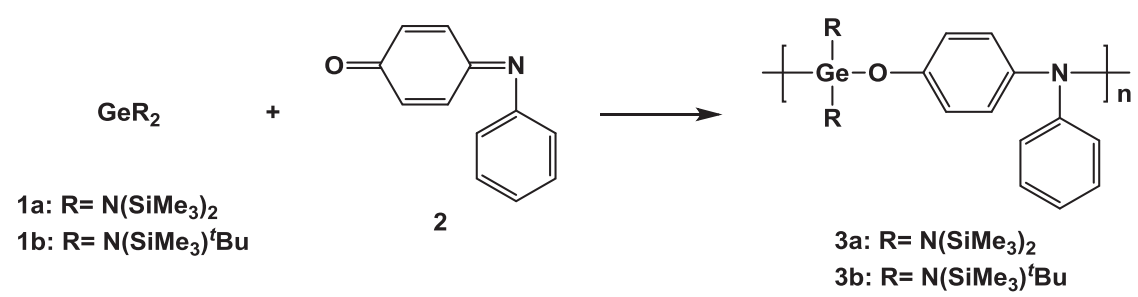

Scheme 1 Alternating copolymerization of germylene (1) with $N$-phenyl-p-quinoneimine.

Table 1 Alternating copolymerization of 1 with $2^{\mathrm{a}}$

\begin{tabular}{cccccc}
\hline Code & Germylene & Copolymer & Yield $(\%)^{\mathrm{b}}$ & $M_{W}{ }^{\mathrm{c}}$ & $M_{W} / M_{n}{ }^{\mathrm{c}}$ \\
\hline 1 & 1a & 3a & 88 & $4.98 \times 10^{4}$ & 2.17 \\
2 & 1b & 3b & 94 & $2.76 \times 10^{4}$ & 2.38 \\
$3^{\mathrm{d}}$ & 1a & 3a & quantity. & $7.05 \times 10^{4}$ & 2.80 \\
\hline
\end{tabular}

a Copolymerization was carried out in toluene at $0{ }^{\circ} \mathrm{C}$ for 2 hours under argon, with the feed of an equimolar amount of $\mathbf{1}$ and $\mathbf{2}$.

bIsolated yields.

'Determined by gel permeation chromatography (GPC).

${ }^{\mathrm{d}}$ Copolymerization was performed in toluene at $0{ }^{\circ} \mathrm{C}$ for 2 hours under argon, with the feed molar ratio $1 \mathrm{a}: 2=100: 90$

p-aminophenol unit alternating in the main chain (Scheme 1). An analogous type of copolymerization was also reported using cyclic and acyclic phosphorus(III) compounds as reductant monomers involving the oxidation of the $\mathrm{P}(\mathrm{III})$ monomer to a $\mathrm{P}(\mathrm{V})$ monomer unit in the product copolymer. ${ }^{25-27}$

\section{EXPERIMENTAL PROCEDURE}

\section{Materials}

$\mathbf{1 a}$ and $\mathbf{1} \mathbf{b}$ were prepared by the reaction of $\mathbf{a} \mathrm{GeCl}_{2} 1,4$-dioxane complex with the appropriate lithium amides, as reported. ${ }^{9,10} 2$ was prepared by the oxidation of p-hydroxydiphenylamine with $\mathrm{Ag}_{2} \mathrm{CO}_{3}$ and then purified by sublimation. ${ }^{28}$ 2,2,6,6-Tetramethylpiperidine-1-oxyl (TEMPO) was obtained from Aldrich (Tokyo, Japan). Toluene and diethyl ether were commercial reagents that were distilled from sodium-benzophenone before use. Acetonitrile was distilled from calcium hydride. Other solvents were commercially available and used as obtained.

\section{Copolymerization}

The copolymerization of $\mathbf{1 a}$ with $\mathbf{2}$ was carried out as follows. A solution of $\mathbf{2}$ in toluene $(0.635 \mathrm{~g}$ of $2,3.47 \mathrm{mmol}$ in $10 \mathrm{ml}$ of toluene) was added to a toluene solution $(5 \mathrm{ml})$ containing $1 \mathrm{a}(1.370 \mathrm{~g}, 3.48 \mathrm{mmol})$ under argon at $0{ }^{\circ} \mathrm{C}$ while stirring. After stirring at $0^{\circ} \mathrm{C}$ for $2 \mathrm{~h}$, the reaction mixture was poured into $150 \mathrm{ml}$ of acetonitrile while stirring. White precipitates were obtained, collected by filtration, and dried in vacuo, this reaction yielded $1.749 \mathrm{~g}(88 \%)$ of copolymer 3a: ${ }^{1} \mathrm{H} \mathrm{NMR}\left(\mathrm{CDCl}_{3}, \delta\right) 0.24$ (s, $\left.\mathrm{SiMe}_{3}, 36 \mathrm{H}\right), 6.6-7.0$ (br. two peaks, $\mathrm{Ar}, 9 \mathrm{H}$ ); ${ }^{13} \mathrm{C} \mathrm{NMR}\left(\mathrm{CDCl}_{3}, \delta\right) 6.0\left(\mathrm{SiMe}_{3}\right), 120.1,121.7,128.1,129.0 \mathrm{CH}$ of $\left.\mathrm{Ar}\right), 137.1$ (C-NPh), 149.5 (C-N), 154.1 (C-O); infrared spectroscopy (IR; $\mathrm{cm}^{-1}$ ) 2950, $2890,1590,1496,1248,1195,873,848$. Anal, calculated for $\left(\mathrm{C}_{24} \mathrm{H}_{45} \mathrm{~N}_{3} \mathrm{OSi}{ }_{4} \mathrm{Ge}\right)_{\mathrm{n}}$ : C, 49.99; H, 7.87; N, 7.29. Found: C, 49.57; H, 7.59; N, 7.49.

The copolymerization of $\mathbf{1} \mathbf{b}$ with $\mathbf{2}$ was performed in a similar manner as described above. Copolymer $\mathbf{3 b}$ was obtained in a $94 \%$ yield, $3 \mathbf{b}:{ }^{1} \mathrm{H}$ NMR $\left(\mathrm{CDCl}_{3}\right.$, \&) 0.28 (br, $\left.\mathrm{SiMe}_{3}, 18 \mathrm{H}\right), 1.53$ (br, Bu, 18H), 6.77 (br. Ar, $\left.9 \mathrm{H}\right) ;{ }^{13} \mathrm{C}$ NMR $\left(\mathrm{CDCl}_{3}, \delta\right) 7.9\left(\mathrm{SiMe}_{3}\right), 34.4\left(\mathrm{Me}_{3} \mathrm{C}\right), 56.2,58.3\left(\mathrm{Me}_{3} \mathrm{C}\right)$ 118.7, 120.2, 127.6, 130.4 (CH of Ar), 136.3 (C-NPh), 150.8 (C-N), 154.8 (C-O); IR $\left(\mathrm{cm}^{-1}\right.$ ) $2955,1593,1500,1238,1179,853,751$. Anal, calculated for $\left(\mathrm{C}_{26} \mathrm{H}_{45} \mathrm{~N}_{3} \mathrm{OSi}_{2} \mathrm{Ge}\right)_{\mathrm{n}}$ : C, 57.36; H, 8.33; N, 7.72. Found: C, 57.03; H, 8.20; N, 7.49.

\section{Stability of the copolymer toward moisture}

Water $(0.8 \mathrm{ml})$ was added to a $16 \mathrm{ml}$ solution of $3 \mathbf{a}(0.082 \mathrm{~g})$ in tetrahydrofuran (THF) under air, and the mixture was stirred for 25 hours. No decrease in molecular weight of the recovered $\mathbf{3 a}$ was observed by gel permeation chromatographic analysis. IR and ${ }^{1} \mathrm{H}$ NMR spectra were identical to those of the starting copolymer sample $\mathbf{3 a}$.

\section{ESR measurement of the germyl radical}

The solutions of $\mathbf{1 a}$ and $\mathbf{2}$ in toluene were separately set into a U-type reaction vessel with an ESR tube connected. The system was degassed by four freezethaw cycles and sealed at reduced pressure at liquid nitrogen temperature. The solution of 2 was added at $20^{\circ} \mathrm{C}$ to the solution of $1 \mathbf{a}$, during which the addition was controlled with a two-way stopcock.

\section{Analytical methods}

${ }^{1} \mathrm{H}$ and ${ }^{13} \mathrm{C}$ NMR measurements were conducted on a Bruker AC-250T spectrometer (Karlsruhe, Germany). IR spectra were obtained on a SHIMAZDU IR-460 spectrometer (Kyoto, Japan). UV-VIS spectra were recorded on a SHIMAZDU UV-160 spectrophotometer using a $10 \mathrm{~mm}$ quartz cell with a teflon silicon septum cap. Gel permeation chromatographic analysis was carried out using chloroform as the eluent and polystyrene as the standard. ESR spectra were measured on a Bruker ESP300 spectrometer. The spin concentration of the germyl radical was determined by comparison with the ESR signal intensity of a solution of TEMPO in toluene with a known concentration.

\section{RESULTS AND DISCUSSION}

\section{Copolymerization reaction}

The present copolymerization is shown in Scheme 1. The germylenes seemed air sensitive, and therefore, the copolymerization was carried out under argon atmosphere as previously reported. ${ }^{9-11}$ Monomer 1 reacted very rapidly in toluene at $0{ }^{\circ} \mathrm{C}$ with an equimolar amount of monomer 2, giving rise to an alternating copolymer (3). The copolymerization results are given in Table 1.

The copolymerization of monomers $\mathbf{1 a}$ and $\mathbf{2}$ gave copolymer $\mathbf{3} \mathbf{a}$ in an $88 \%$ yield and having a high molecular weight $\mathrm{M}_{w}=4.98 \times 10^{4}$ (Code 1). The ${ }^{1} \mathrm{H}$ NMR spectrum of copolymer $\mathbf{3 a}$ (Figure 1a) shows a large singlet peak a at $\delta 0.24$ due to $\mathrm{Si}\left(\mathrm{CH}_{3}\right)_{3}(36 \mathrm{H})$ and broad multiplet peaks b at $\delta 6.6-7.0$ due to the aromatic protons (total $9 \mathrm{H}$ ). In the ${ }^{13} \mathrm{C}$ NMR spectrum of copolymer $3 \mathrm{a}$ (Figure $1 \mathrm{~b}$ ), a large singlet peak a is apparent at $\delta 6.0$ due to $\mathrm{Si}\left(\mathrm{CH}_{3}\right)_{3}$, specific singlet peaks b appear at $\delta 137.1$ due to $\mathrm{Ge}-\mathrm{C}-{ }_{\mathrm{NC} 6 \mathrm{H} 5}, \mathrm{c}$ appears at 149.5 due to Ge-N-C-, d appears at $\delta 154.1$ due to Ge-O-C-, and other aromatic $\mathrm{CH}$ carbon peaks appear at $\delta 120-129$. For the peak assignment, ${ }^{13} \mathrm{C}$ NMR spectra of monomer 2 and of $N$-phenyl-p-aminophenol were taken as reference (data not shown). These NMR spectral data supported the structure of copolymer $3 \mathbf{a}$ having an alternating arrangement of a tetravalent germanium unit and $N$-phenyl- $p$ aminophenol unit in the main chain.

Furthermore, the IR spectrum and elemental analysis of $\mathbf{3 a}$ clearly supported the structure of $3 a$. A significant feature of the IR spectrum of monomer 2 was the absence of $v(\mathrm{C}=\mathrm{O})$ and $v(\mathrm{C}=\mathrm{N})$, which were observed at $1642 \mathrm{~cm}^{-1}$ and $1615 \mathrm{~cm}^{-1}$, respectively. The absorption due to stretching of aromatic rings was observed at 1590 and $1496 \mathrm{~cm}^{-1}$ for copolymer $3 \mathbf{a}$, being similar to those of 
a

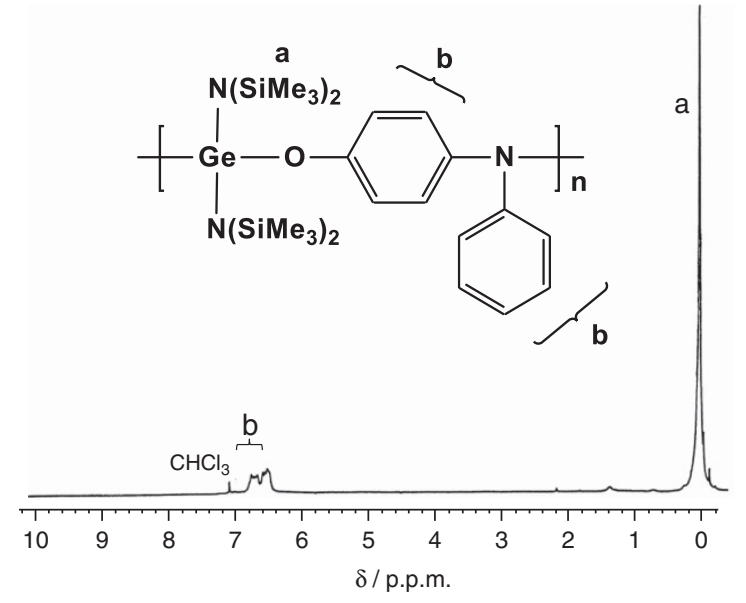

b

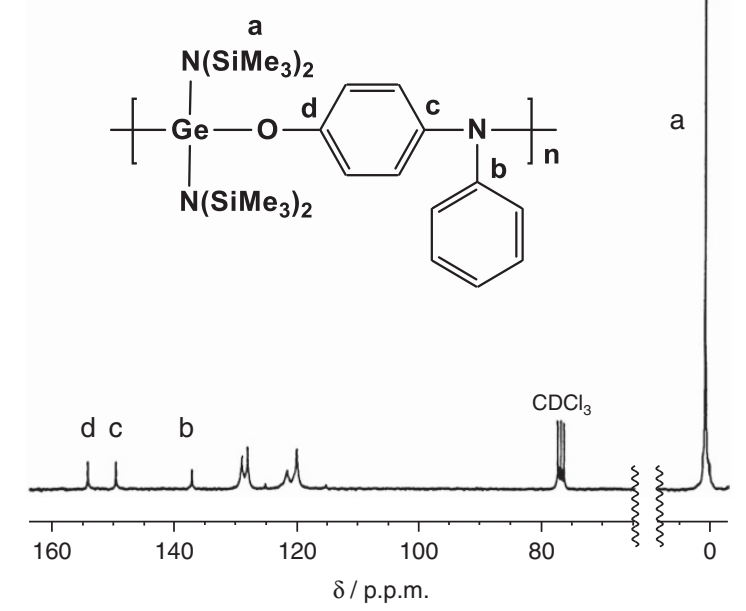

Figure $1{ }^{1} \mathrm{H}$ NMR spectrum (a) and ${ }^{13} \mathrm{C}$ NMR spectrum (b) of copolymer $3 \mathbf{a}$ (both in $\mathrm{CDCl}_{3}$ ).

p-hydroxydiphenylamine $\left(1591 \mathrm{~cm}^{-1}\right.$ and $1501 \mathrm{~cm}^{-1}$, respectively). Anal, calculated for $\left(\mathrm{C}_{24} \mathrm{H}_{45} \mathrm{~N}_{3} \mathrm{OSi}_{4} \mathrm{Ge}\right)_{\mathrm{n}}$ : C, 49.99; H, 7.87; N, 7.29. Found: C, 49.57; H, 7.59; N, 7.49.

Similarly, the copolymerization of $\mathbf{1 b}$ with $\mathbf{2}$ was carried out (Code 2), giving rise to the alternating copolymer $\mathbf{3 b}$ in a high yield with high molecular weight. Compared with comonomer $\mathbf{1 a}, \mathbf{1 b}$ possessed a more sterically hindered $t$-butyl group, yet produced the alternating copolymer $\mathbf{3 b}$ in a similar manner.

During the copolymerization, 1 (reductant monomer) was oxidized from $\mathrm{Ge}$ (II) to $\mathrm{Ge}(\mathrm{IV})$, whereas 2 (oxidant monomer) was reduced from a $p$-quinoneimine structure to a $p$-aminophenol unit structure. Thus, the present reaction is a typical example of 'oxidation-reduction copolymerization' as reported before. ${ }^{9-24}$ The high reactivity of 1 toward 2 involving a carbon-nitrogen double bond toward a carboncarbon double bond was noted in $\alpha, \beta$-unsaturated carbonyl compounds. ${ }^{22,23}$

The copolymers were white fine powders and were soluble in $n$-hexane, benzene and chloroform, whereas they were insoluble in acetonitrile and acetone. They were stable in air and the molecular weight did not decrease after being kept in air for several months, indicating that they can tolerate oxidation by oxygen and hydrolysis by

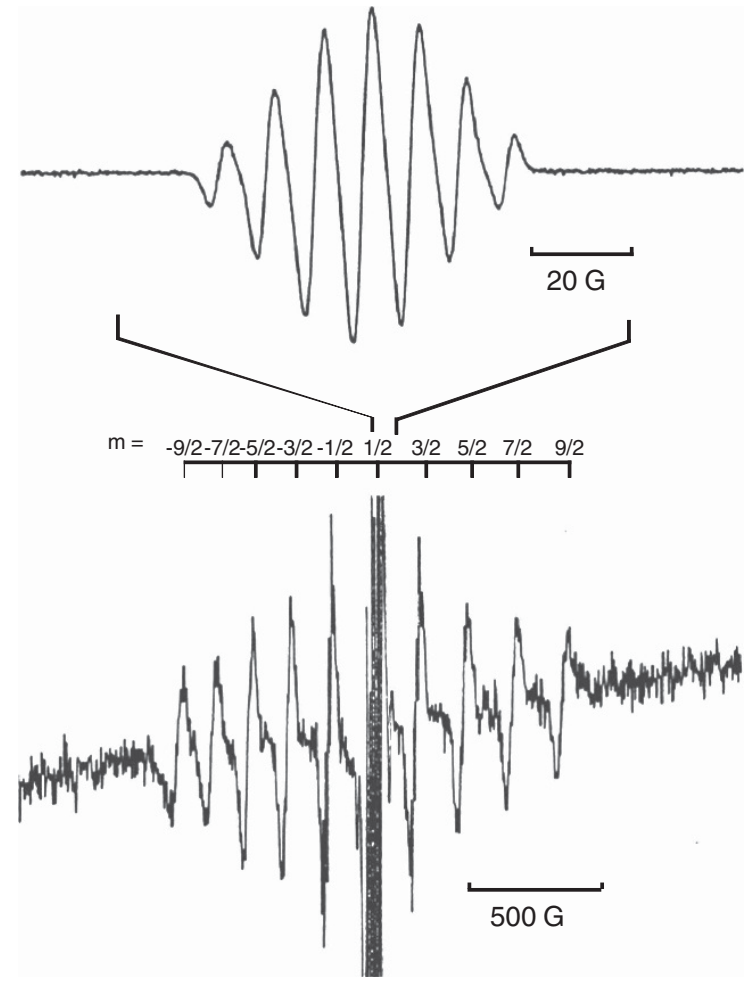

Figure 2 ESR spectrum of the reaction mixture of 1 a with $60 \mathrm{~mol} \%$ of 2 measured at $20^{\circ} \mathrm{C}$.

moisture. The Si-N, Ge-N and Ge-O bonds are usually dipolar and readily cleaved by a protic solvent. ${ }^{29}$ For example, hexamethyldisilazane is immediately hydrolyzed in aqueous methanol. ${ }^{30}$ An attempt to hydrolyze copolymer $3 \mathbf{a}$ was made by keeping it in THF-water mixture for 25 hours. Gel permeation chromatographic analysis of the sample 3a showed no molecular weight decrease. Additionally, its IR spectrum showed the absence of absorption for $\nu(\mathrm{N}-\mathrm{H})$, indicating that hydrolysis of the bis(trimethylsilyl)amino group did not occur. These facts strongly indicate that bulky substituents on the germanium in 3a prevent the water molecule from approaching the dipolar bonds.

\section{ESR study}

Oxidation-reduction reactions normally involve an electron transfer process to give a radical ion pair or a biradical species. Reduction of a carbonyl group with a Grignard reagent is a typical example. ${ }^{31}$ In our previous study on the alternative copolymerization of germylene $\mathbf{1}$ and a $p$-benzoquinone derivative, copolymerization via a biradical mechanism was verified by ESR spectroscopy and trapping experiments. $^{10}$

For the present reactions, the copolymerization mechanism was similarly considered owing to the similarity in structure between 2 and p-benzoquinone. To investigate this point in more detail, an ESR study was performed. When $2(60 \mathrm{~mol} \%$ toward 1a) was added to the toluene solution of $1 \mathrm{a}$, the color of the solution turned from yellow to deep violet. In the ESR spectrum of the reaction mixture (Figure 2), a 1:3:6:7:6:3:1 septet signal was clearly observed, which was ascribed to the germyl radical (4) located at both propagating polymer ends. The germyl radical was bonded to two equivalent bis(trimethylsilyl)amino groups and selectively bonded to the third nitrogen atom of the terminal $p$-aminophenol unit, whose structure is indicated as (a) in Scheme 2. Another possible germyl radical bonded to the oxygen atom of the $p$-aminophenol unit was not observed, indicating that germyl 
a<smiles></smiles>

4: $\mathrm{R}=\mathrm{N}\left(\mathrm{SiMe}_{3}\right)_{2}$

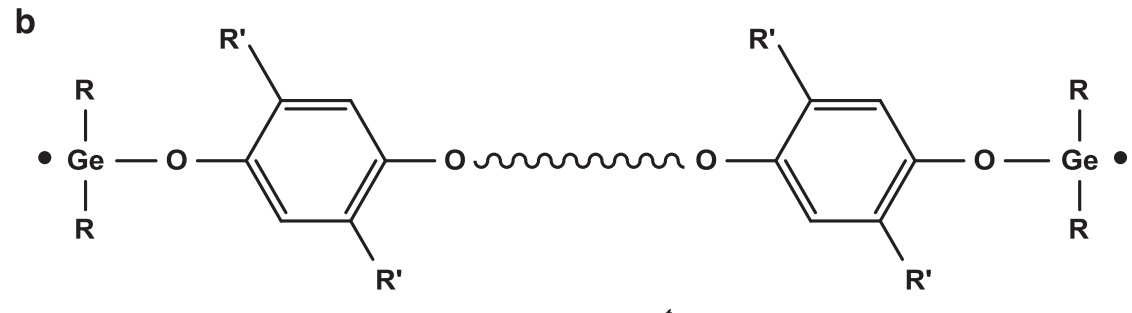

$$
\begin{aligned}
& 5 a: R=N\left(\mathrm{SiMe}_{3}\right)_{2}, \mathrm{R}^{\prime}={ }^{t} \mathrm{Bu} \\
& 5 \mathrm{~b}: \mathrm{R}=\mathrm{N}\left(\mathrm{SiMe}_{3}\right)_{2}, \mathrm{R}^{\prime}={ }^{t} \mathrm{Amyl}
\end{aligned}
$$

Scheme 2 (a) Germyl radicals (4) bonded to three nitrogen atoms formed from the reaction of 1a and 2 (100:60 molar ratio), and (b) germyl radicals (5) bonded to two nitrogen atoms and one oxygen atom. ${ }^{10}$

\begin{tabular}{|c|c|c|c|}
\hline Germyl radical & hfc value $A\left({ }^{73} \mathrm{Ge}\right) / \mathrm{G}$ & g-value & Ref. \\
\hline - $\mathrm{GeMe}_{3}$ & 83 & 2.0104 & 10 \\
\hline - $\mathrm{Ge}\left[\mathrm{C}_{6} \mathrm{H}^{t} \mathrm{Bu}-2-\mathrm{Me}_{3}-4,5,6\right]_{3}$ & 85 & 2.0049 & 36 \\
\hline$\cdot-\mathrm{Ge}\left[\mathrm{CH}\left(\mathrm{SiMe}_{3}\right)_{2}\right]_{3}$ & 92 & 2.0078 & 36 \\
\hline Germyl radical $4(A)$ & 158 & 1.9988 & Present study \\
\hline Germyl radical 5a (B) & 166 & 1.9986 & 10 \\
\hline Germyl radical 5b (B) & 167 & 1.9985 & 10 \\
\hline - $\mathrm{Ge}\left[\mathrm{N}\left(\mathrm{SiMe}_{3}\right)_{2}\right]_{3}$ & 171 & 1.9991 & 32,33 \\
\hline - $\mathrm{Ge}\left[\mathrm{N}\left(\mathrm{SiMe}_{3}\right)^{t} \mathrm{Bu}\right]_{3}$ & 173 & 1.9998 & 32,33 \\
\hline - $\mathrm{GeCl}_{3}$ & 220 & - & 35 \\
\hline
\end{tabular}

Table 2 ESR parameters for germyl radicals

radical 4 was linked to three nitrogen atoms. ${ }^{32}$ If the germyl radical were bonded to the oxygen atom of the terminal $p$-aminophenol unit, the radical would show a 1:2:3:2:1 quintet signal due to the bonding to two bis(trimethylsilyl)amino groups. ${ }^{10}$ The coupling constant $\left(A_{\mathrm{N}}=9.63 \mathrm{G}\right)$ was due to the nitrogen atom $(I=1)$ on the germanium. The fact that only one value of the coupling constant was observed suggests that the values because of the nitrogen atom of the terminal $p$-aminophenol unit and the two equivalent nitrogen atoms of bis(trimethylsilyl)amino groups were almost equal. The $A_{\mathrm{N}}$ value for 4 was approximately $1 \mathrm{G}$ smaller than that $\left(A_{\mathrm{N}}=10.6 \mathrm{G}\right)$ of the germyl radical $\bullet \mathrm{Ge}\left[\mathrm{N}\left(\mathrm{SiMe}_{3}\right)_{2}\right]_{3}$ due to the three equivalent bis (trimethylsilyl)amino groups generated by the photolysis of $1 \mathbf{a}^{32}$ The decreased $A_{\mathrm{N}}$ value was most likely due to the decreased spin density on the nitrogen atoms from delocalization of the unpaired electron into the aromatic ring. By comparing the peak intensity with that of the known amount of TEMPO, approximately $0.3 \%$ of the germyl radical based on the added 2 was observed at this point.

Among the five isotopes of germanium, only ${ }^{73} \mathrm{Ge}$ has a non-zero nuclei spin value $(I=9 / 2)$, which gives ten satellite peaks (Figure 2). Because the natural abundance of ${ }^{73} \mathrm{Ge}$ is $7.6 \%$, the satellite's intensity is much smaller than that of the main signal. The hyperfine coupling

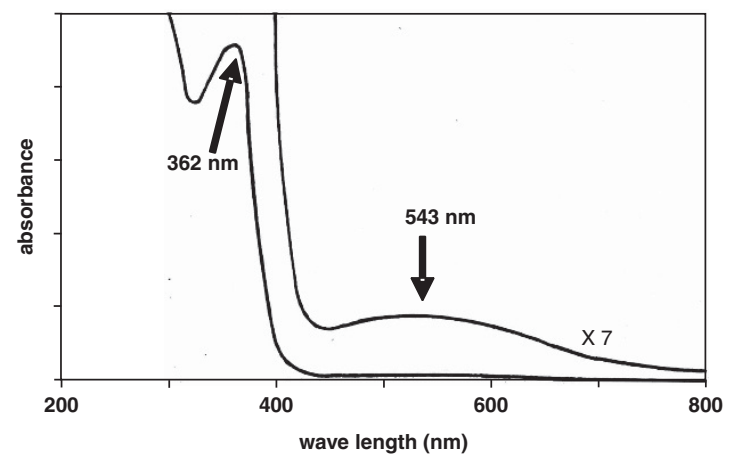

Figure 3 UV-VIS spectrum of the reaction mixture of 1 a and $50 \mathrm{~mol} \%$ of 2 in diethyl ether at $20^{\circ} \mathrm{C}$.

(hfc) constant of $4\left(A_{\mathrm{Ge}}=158 \mathrm{G}\right)$ due to ${ }^{73} \mathrm{Ge}$ was slightly smaller than that of the previously studied radicals having the $\bullet \mathrm{Ge}\left[\mathrm{N}\left(\mathrm{SiMe}_{3}\right)_{2}\right]_{2}$ [OAr] structure, as given in $\mathbf{5 a}$ and $\mathbf{5 b}$ (Scheme $2 \mathrm{~b}$ ), $A_{\mathrm{Ge}}=166 \mathrm{G}$ and $167 \mathrm{G}$, respectively. ${ }^{10}$ The hfc value of 4 was also smaller than that of the radical $\bullet \mathrm{Ge}\left[\mathrm{N}\left(\mathrm{SiMe}_{3}\right)_{2}\right]_{3}\left(A_{\mathrm{Ge}}=171 \mathrm{G}\right){ }^{32,33}$ The hfc constant due to the center atom $\mathrm{M}$ with a non-zero nuclei spin for the $\bullet \mathrm{MX}_{3}$ type radical is generally associated with geometry of the radical. The $A_{\mathrm{M}}$ value increases with decreasing $p$-character of the orbital on which the unpaired electron resides. Therefore, the increased $A_{\mathrm{M}}$ value indicated greater deviation from planar geometry of the radical. ${ }^{34}$ The larger $A_{\mathrm{Ge}}$ value for 4 compared with that of the radical $\bullet \mathrm{GeMe}_{3}\left(A_{\mathrm{Ge}}=83 \mathrm{G}\right)$ indicated a more pyramidalized radical; however, the $A_{\mathrm{Ge}}$ value was less than the almost tetrahedral radical $\bullet \mathrm{GeCl}_{3}\left(A_{\mathrm{Ge}}=220 \mathrm{G}\right){ }^{35}$ The presence of the electronegative nitrogen atoms and of the $N$-phenyl substituent on the main-chain nitrogen atom, all three bonded to the germanium radical center, would force a geometry more similar to the pyramidal geometry of radical 4. Additionally, the smaller $g$-value implies the increased tetrahedral character of the germyl radical geometry, although all of the hfc values are in a very narrow range. The $g$-value for $4(g=1.9988)$ was close to those for $5 \mathbf{a}(1.9986)$, 


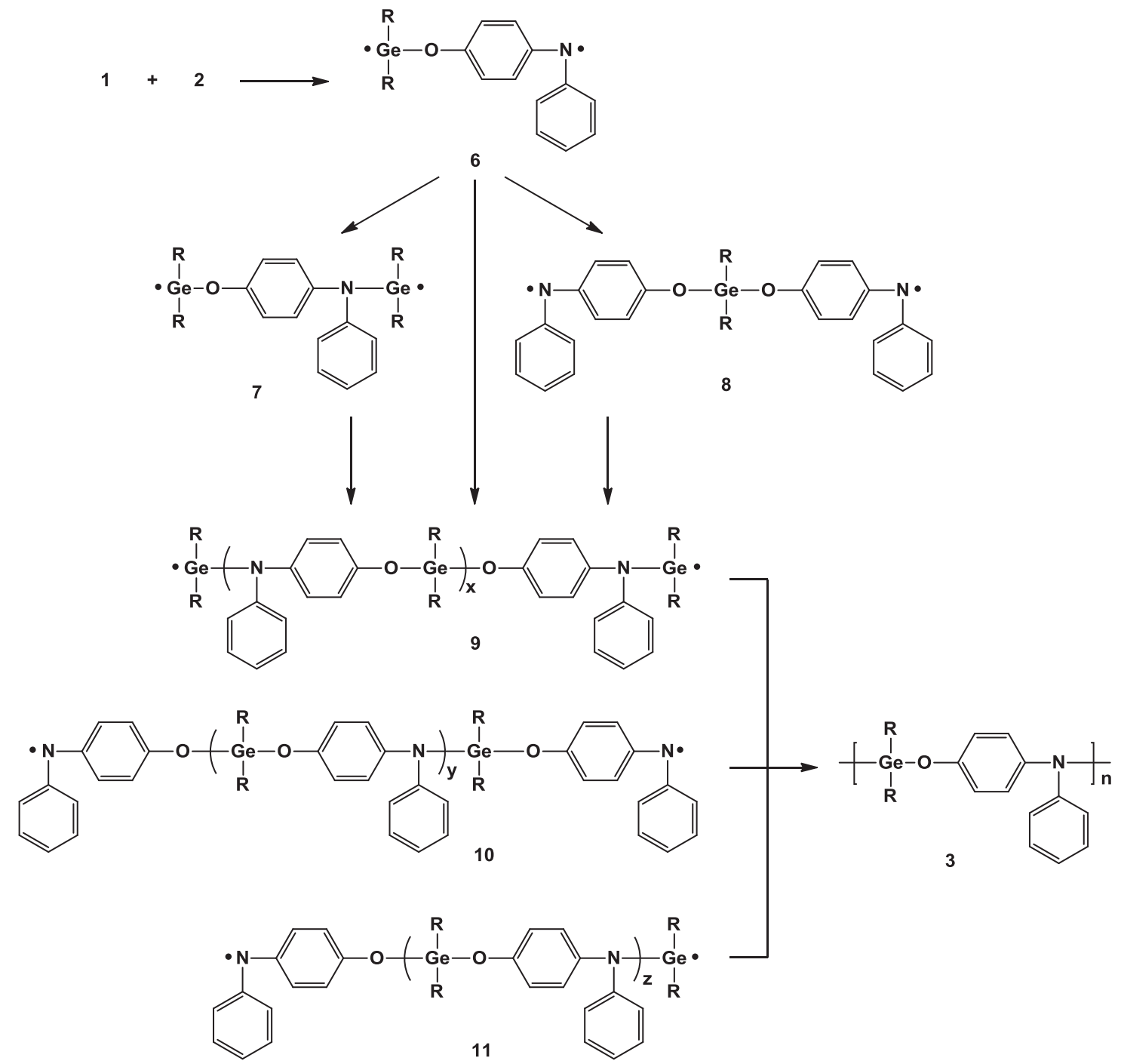

Scheme $\mathbf{3}$ Postulated biradical mechanism for the alternating copolymerization of $\mathbf{1}$ with $\mathbf{2}$.

5b (1.9985) and $\bullet \mathrm{Ge}\left[\mathrm{N}\left(\mathrm{SiMe}_{3}\right)_{2}\right]_{3}$ (1.9991), suggesting that these four radicals have a similar geometry on the centered germanium. ${ }^{10}$ For clarity, these values together with two additional radicals ${ }^{36}$ are shown in Table 2.

The germyl radical 4 showed great persistency; the half-life time $\left(t_{1 / 2}\right)$ was approximately 1.3 hours in toluene at $20^{\circ} \mathrm{C}$. The steric hindrance most likely prevented the $\mathrm{Ge}-\mathrm{Ge}$ bond formation via the coupling of the two germyl radicals, which normally causes the instability.

\section{UV-VIS spectrum}

The spectrum of the reaction mixture of $1 \mathrm{a}$ and $50 \mathrm{~mol} \%$ of 2 in diethyl ether was measured (Figure 3 ). When 1a and 2 were mixed, the solution color turned to dark violet. The absorption peak at $362 \mathrm{~nm}$ was ascribed to the remaining 1a, whereas the peak at $446 \mathrm{~nm}$ due to 2 was not detected. Thus, the very broad absorption at $543 \mathrm{~nm}$ observed in the increased intensity spectrum $(\times 7)$ was most likely ascribed to the germy radical 4 , which was responsible for the dark violet color. When another $50 \mathrm{~mol} \%$ of 2 was added to the reaction mixture, the color of the solution turned from dark violet to pale yellow orange, and the ESR signal due to 4 completely disappeared.
In the course of this copolymerization, only the germyl radical showed an absorption signal due to reactive species.

\section{Copolymerization mechanism}

Based on the above observations, a plausible mechanism of copolymerization of $\mathbf{1}$ with $\mathbf{2}$ is described as a radical process, more likely a biradical process, in the following manner (Scheme 3). The first step is the formation of the biradical 6 via an oxidation-reduction process. This biradical possesses two unpaired electrons: one located on the germanium atom and the other delocalized on the $\mathrm{N}$-aromatic rings. The Ge-O bond formation is more favorable because the imino group of $\mathbf{2}$ is sterically restricted due to the phenyl substituent. Additionally, the radical $\bullet \mathrm{N}-\mathrm{C}_{6} \mathrm{H}_{5}$ is more stable due to the delocalization of unpaired electrons on the phenyl ring(s). Then, $\mathbf{1}$ attacks $\mathbf{6}$ to produce the germyl diradicals 7 , whereas 2 attacks 6 to give the anilino biradicals 8. Successive reactions among monomers (1 or 2), 6, 7 and $\mathbf{8}$ produce copolymer $\mathbf{9}$ with two germyl radicals, copolymer 10 with two anilino radicals and copolymer $\mathbf{1 1}$ with a germyl radical and an anilino radical at the polymer end. The radical coupling reactions between the germyl radical part and the anilino radical part of biradicals $\mathbf{6 - 1 1}$, as well as these radicals-monomer ( 1 or 2$)$ reactions, 
eventually occur, resulting in the alternating copolymer 3 . When excess $\mathbf{1}$ is used, an equimolar amount of $\mathbf{1}$ and $\mathbf{2}$ is consumed to yield copolymer biradicals such as $\mathbf{1 1}$. The remaining 1 reacts with the anilino radical to give the germyl diradicals, such as $\mathbf{9}$, as a relatively stable species. Among the biradicals, 6-11 (except 9) are most likely short-lived species and are thus difficult to directly observe.

It is assumed that among all of the reaction steps in Scheme 3, the formation of $\mathbf{6}$ from 1 and 2 via the oxidation-reduction process is most likely the most rapid. This assumption explains the production of a high molecular weight alternating copolymer $3\left(M_{\mathrm{w}}=7.05 \times 10^{4}\right)$, even with the feed ratio of $1 \mathbf{a}: 2=100: 90$, as shown by Code 3 (Table 1). The behaviors of this copolymerization do not resemble the polycondensation of two bifunctional monomers but instead resemble the rapid initiation type polymerization as already noted, ${ }^{10}$ where the initiation is the reaction of $\mathbf{1}$ and $\mathbf{2}$ to form $\mathbf{6}$. Then, $\mathbf{6}$ most likely behaves as a propagating monomer, giving rise to the alternating copolymer 3. In this sense, $10 \%$ excess of comonomer 1 did not disturb the production of a high molecular weight copolymer, which differs from the normally observed results in polycondensation reactions.

\section{CONCLUSION}

An oxidation-reduction, alternating copolymerization of a germylene (1a or $\mathbf{1 b}$ ) with a quinoneimine (2) has been reported, where $\mathbf{1}$ was used as a reductant monomer and $\mathbf{2}$ was employed as a new oxidant monomer. The reaction took place smoothly at $0{ }^{\circ} \mathrm{C}$ without added catalyst or initiator to produce alternating copolymers ( $\mathbf{3} \mathbf{a}$ and $\mathbf{3 b}$ ) that have high molecular weights in high yields. The copolymers were soluble in an organic solvent and tolerant of hydrolysis. ESR studies of the reaction revealed that the copolymerization proceeded most plausibly via a biradical mechanism.

1 Neumann, W. P. Germylenes and stannylenes. Chem. Rev. 91, 311-334 (1991).

2 Sweeder, R. D., Gdula, R. L., Ludwig, B. J., Holl, M. M. B., Kampf, J. W. Germylene reactions with quinones shed light on germylene phenone equilibria. Organometallics 22, 3222-3229 (2003)

3 Mizuhata, Y., Sasamori, T., Tokitoh, N. Stable heavier carbene analogues. Chem. Rev. 109, 3479-3511 (2009).

4 Asay, M., Jones, C., Driess, M. N-Heterocyclic carbene analogues with low-valent group 13 and group 14 elements: Syntheses, structures, and reactivities of a new generation of multitalented ligands. Chem. Rev. 111, 354-396 (2011).

5 Li, Y., Mondai, K. C., Stollberg, P., Zhu, H., Roesky, H. W., Herbst-Irmer, R., Stalke, D., Fliegl, $\mathrm{H}$. Unusual formation of a $\mathrm{N}$-heterocyclic germylene via homolytic cleavage of a C-C bond. Chem. Commun. 50, 3356-3358 (2014).

6 Fjeldberg, T., Haaland, A., Schilling, B. E. R., Lappert, M. F., Thorne, A. J. Subvalent group $4 \mathrm{~B}$ metal alkyls and amides. Part 8. Germanium and tin carbene analogues MR $\left[\mathrm{M}=\mathrm{Ge}\right.$ or $\left.\mathrm{Sn}, \mathrm{R}=\mathrm{CH}\left(\mathrm{SiMe}_{3}\right)_{2}\right]$ : synthesis and structures in the gas phase (electron diffraction); molecular-orbital calculations for $\mathrm{MH}_{2}$ and $\mathrm{GeMe}_{2}$. J. Chem. Soc. Dalton Trans. 1551-1556 (1986).

7 Kobayashi, S., Cao, S. Synthesis of polygermanes by ligand substitution polymerization on the 1,4-dioxane complex of germanium dichloride with organolithium compounds. Chem. Lett. 1385-1388 (1993).

8 Cao, S., Kobayashi, S. Synthesis of new germanium-containing oligomers by polyaddition reaction of a bisgermylene to organic halides. Macromol. Reports A31 (SUPPL. 5), 627-634 (1994).

9 Kobayashi, S., Iwata, S., Abe, M., Shoda, S. New germanium-containing polymers via alternating copolymerization of a germylene with $p$-benzoquinone derivatives. J. Am. Chem. Soc. 112, 1625-1626 (1990).

10 Kobayashi, S., Iwata, S., Abe, M., Shoda, S. A novel redox process for the construction of germanium-containing polymers by utilizing germylenes and $p$-benzoquinone derivatives: first clear-cut evidence for a biradical propagation mechanism in polymerization chemistry. J. Am. Chem. Soc. 117, 2187-2200 (1995).

11 Kobayashi, S., Iwata, S., Hiraishi, M. Novel 2:1 periodic copolymers from cyclic germylenes and p-benzoquinone derivatives. J. Am. Chem. Soc. 116, 6047-6048 (1994).

12 Kobayashi, S., Iwata, S., Yajima, K., Yagi, K., Shoda, S. Poly(germanium enolate): a new class of polymer having a germanium enolate structure in the main chain. J. Am. Chem. Soc. 114, 4929-4931 (1992).

13 Kobayashi, S., Shoda, S. A novel metal-containing polymer: poly(germanium enolate). Adv. Mater. 5, 57-59 (1993).

14 Shoda, S., Iwata, S., Yajima, K., Yagi, K., Ohnishi, Y., Kobayashi, S. Synthesis of germanium enolate polymers from germylene monomers. Tetrahedron 53 15281-15295 (1997).

15 Kobayashi, S., Iwata, S., Kim, H. J., Shoda, S. Novel oxidation-reduction copolymerization of a germylene with ethylene or propylene sulfide producing a $1: 1: \alpha$ periodic copolymer. Macromolecules 29, 486-488 (1996).

16 Shoda, S., Iwata, S., Kim, H. J., Hiraishi, M., Kobayashi, S. Poly(germanium thiolate): a new class of organometallic polymers having a germanium-sulfur bond in the main chain. Macromol. Chem. Phys. 197, 2437-2445 (1996).

17 Kobayashi, S., Cao, S. Copolymerization of a germylene with acetylene monomers by Rhodium catalysis. Chem. Lett. 25-28 (1993).

18 Kobayashi, S., Iwata, S., Shoda, S. Oxidation-reduction alternating copolymerization of stannylenes with p-benzoquinone derivatives. Acta. Polymer. 46, 471-475 (1995).

19 Kobayashi, S. in Ring-opening Polymerization (ed. Brunelle D. J.) Chapter 12 (Hanser Publishers: New York, 1993).

20 Shoda, S., Uyama, H., Kobayashi, S. in Catalysis in Precision Polymerization (ed. Kobayashi S.) Chapter 9 (John Wiley \& Sons: Chichester, England, 1997).

21 Kobayashi, S., Shoda, S., Iwata, S. in Desk Reference of Functional Polymers (ed. Arshady R.) 169-181 (American Chemical Society, Washington, DC, 1997).

22 Kobayashi, S., Iwata, S., Shoda, S. Synthesis of cyclic germanium enolates from bis[bis (trimethylsilyl)amido]germanium (II) and $\alpha, \beta$-unsaturated carbonyl compounds. Chem. Exp. 4, 41-44 (1989)

23 Iwata, S., Shoda, S., Kobayashi, S. Synthesis of a novel cyclic germanium enamine from germylene and 2-vinylpyridine and its stereoselective Aldol type reaction with aldehydes. Organometallics 14, 5533-5536 (1995).

24 Kobayashi, S., Iwata, S., Abe, M., Yajima, K., Kim, H. J., Shoda, S. A germylene and stannylene as polymerization of comonomer and initiator. Macromol. Chem., Macromol. Symp. 54/55, 225-231 (1992).

25 Kobayashi, S., Okawa, M., Niwano, M., Saegusa, T. Redox 1:1 alternating copolymer ization of cyclic acyl phosphonite with 4,4'-diphenoquinones. Polym. Bull. 5 331-333 (1981).

26 Saegusa, T., Kobayashi, S., Kobayashi, T. Polyphosphoranylation of $p$-benzoquinone with acyclic and cyclic phosphorus(III) compounds having aryl and aryloxy groups. Macromolecules 14, 463-464 (1981).

27 Kobayashi, S., Lundmark, S., Kadokawa, J., Albertsson, A. C. Ring-opening-closing alternating copolymerization of a cyclic phosphonite with a dialdehyde. Macromolecules 24, 2129-2131 (1991)

28 Fetizon, M., Balogh, V., Golfier, M. Oxidations with silver carbonate/celite. V. Oxidations of phenols and related compounds. J. Org. Chem. 36, 1339-1341 (1971).

29 Rivière, P., Rivière-Baudet, M., Satge, G. in Comprehensive Organometallic Chemistry (eds Wilkinson G., Stone F. G., Abel E. W.) Vol. 2 399-514 (Pergamon Press: Oxford, 1982).

30 Armitage, D. A. in Comprehensive Organometallic Chemistry (eds Wilkinson G., Stone F. G., Abel E. W.) Vol. 2, 1-203 (Pergamon Press: Oxford, 1982).

31 Maruyama, K. The appearance of free radicals during Grignard reactions. Bull. Chem Soc. Jpn 37, 897-898 (1964).

32 Hudson, A., Lappert, M. F., Lednor, P. W. Subvalent group 4B metal alkyls and amides. Part 4. An electron spin resonance study of some long-lived photochemically synthesized trisubstituted silyl, germyl, and stannyl radicals. J. Chem. Soc. Dalton Trans. 2369-2375 (1976).

33 Gynane, M. J. S., Harris, D. H., Lappert, M. F., Power, P. P., Rivière, P., Rivière-Baudet, M. Subvalent group $4 \mathrm{~B}$ metal alkyls and amides. Part 5. The synthesis and physical properties of thermally stable amides of germanium(II), tin(II), and Lead(II). J. Chem. Soc. Dalton Trans. 2004-2009 (1977).

34 Fessenden, R. W., Schuler, R. H. ESR spectra and structure of the fluorinated methyl radicals. J. Chem. Phys. 43, 2704-2712 (1965).

35 Roncin, J., Debuyst, R. ESR study of line position and width in $\gamma$-irradiated polycrystalline globular $\mathrm{GeCl}_{4}$. Structure and motion of the $\mathrm{GeCl}_{3}$ radical. J. Chem. Phys. 51, 577-583 (1969).

36 Bona, M. A. D., Cassani, M. C., Keates, J. M., Lawless, G. A., Lappert, M. F., Stürmann M., Weidenbruch, M. Magnetic resonance spectroscopic studies of a tetraaryldistannene and -digermene $\left[\mathrm{M}_{2} \mathrm{R}_{4}\right]\left(\mathrm{R}=\mathrm{C}_{6} \mathrm{HBu}^{\mathrm{t}}-2-\mathrm{Me}_{3}-4,5,6-\right.$ and $\mathrm{M}=\mathrm{Sn}$ or $\left.\mathrm{Ge}\right)$. J. Chem. Soc. Dalton Trans. 1187-1190 (1998). 